\title{
Cinema, Antropologia e a construção de mundos possíveis: o caso dos festivais de cinema da diversidade sexual
}

\author{
Marcos Aurélio da Silva' \\ Universidade Federal de Mato Grosso
}

Resumo: O artigo pretende uma discussão sobre as relações entre cinema e antropologia, mas a partir do ponto de vista da ficcionalidade ou a possibilidade de construção de mundos possíveis. Antropólogos das últimas décadas têm estado atentos ao caráter autoral do trabalho etnográfico e sua relação com uma estética da literatura, o que não significou necessariamente tomar a disciplina por uma não ciência. Da mesma forma, cineastas e teóricos do cinema se debatem sobre a possibilidade de se pensar o cinema, independente se ficção ou documentário, enquanto a constituição de uma realidade possível. A partir da pesquisa de campo em festivais de cinema de gênero e da diversidade sexual, em que os sujeitos pesquisados realizam performances de um mundo desejável, busca-se problematizar essa ideia de construção de mundos compartilhada entre cinema e antropologia, apontando enfim para as possibilidades de uma antropologia do cinema e sua etnografia das multissensorialidades.

Palavras-chave: cinema; festivais; antropologia visual; etnografia.

\footnotetext{
1 Professor permanente do PPGAS/UFMT, membro do Grappa. Este trabalho só foi possível graças ao apoio institucional do Núcleo de Antropologia do Contemporâneo (TRANSES) da Universidade Federal de Santa Catarina, do Instituto Brasil Plural (IBP/UFSC), do Grupo de Pesquisa em Antropologia do Contemporâneo - Sujeitos, Sociabilidades e Visualidades (GPAC/UFMT), e aos apoios financeiros em forma de bolsa da Capes e do CNPq. Pesquisa as audiovisualidades nas paisagens urbanas, com destaque a carnavais, paradas e festivais de cinema da diversidade sexual.
} 


\title{
Cinema, Anthropology and the and the making of possible worlds: the case of film festivals of sexual diversity
}

\begin{abstract}
The article aims a discussion of the relationship between film and anthropology, but from the point of view of fictionality or the possibility of construction of possible worlds. Anthropologists of recent decades have been aware to authorial character of ethnographic work and its relation to an aesthetics of literature, which does not necessarily mean taking the discipline by not science. Similarly, filmmakers and film theorists struggle about the possibility of thinking the cinema, regardless of whether fiction or documentary, while setting up a possible reality. From the field research in festivals of gender and sexual diversity cinema, in which the subjects surveyed perform a desirable world, we seek to discuss the idea of building worlds shared by films and anthropology, finally pointing to the possibilities of an anthropology of cinema and its ethnography of multissensorialities.
\end{abstract}

Keywords: Cinema; festivals; visual anthropology; ethnography.

\section{Cine, Antropología y la construcción de mundos possibiles: el caso de los festivales de cine de la diversidad sexual}

Resúmen: El artículo tiene la intención de un análisis de la relación entre el cine y la antropología, pero desde el punto de vista de la ficcionalidad o la posibilidad de la construcción de los mundos posibles. Los antropólogos de las últimas décadas están atentos al carácter autoral del trabajo etnográfico y su relación con una estética de la literatura, lo que no significa necesariamente que tomar la disciplina por no ciencia. Del mismo modo, cineastas y teóricos del cine luchan por la posibilidad de pensar el cine, con independencia de que la ficción o documental, mientras que la creación de una realidad posible. A partir de la investigación de campo en los festivales de género y la diversidad sexual del cine, en el que los sujetos realizan performances de un mundo deseable, buscamos para discutir la idea de construir mundos compartidos por cine y antropología, finalmente, señalando las posibilidades de una antropología del cine y su etnografía de multissensorialidades.

Palabras clave: cine; festivales; antropología visual; etnografia. 
Muito já se falou - sem se esgotar o assunto - sobre as relações entre imagem e antropologia: a contemporaneidade dos dois campos, os desenvolvimentos de uma antropologia que produz fotografia e audiovisual desde seus fundadores (BARBOSA e CUNHA, 2006: 16), e é cada vez mais crescente a preocupação não apenas com o cinema, mas com as tecnologias da comunicação nas produções contemporâneas de coletividades e subjetividades (MALUF et al., 2010: 11) - algo que pode parecer novo mas muitas vezes apenas se junta a regimes já consagrados como a religião ou o estado. Quero enfocar aqui, mais especificamente, as relações que podem ser pensadas entre cinema e antropologia, quando olhamos estes dois campos a partir da perspectiva de construção de mundos. Talvez não seja preciso retornar à história da antropologia para lembrarmos que a etnografia cada vez mais tem sido pensada como um dos muitos produtos da disciplina, guardando importantes relações com a estética da literatura e a questão do autor. Assim como também não é nenhuma tarefa difícil pensar cada filme como um mundo construído à parte, cuja existência varia de acordo com a duração do filme e se torna palpável pelo período em que estamos assistindo.

Reconheço que as preocupações que fazem parte do que estamos chamando de Antropologia no/do/com cinema já trilharam e trilham o caminho da Antropologia Visual, mas não é a partir dela que essa discussão vai começar. Ou melhor, essa discussão parte sim da Antropologia Visual, mas também e com a mesma intensidade de campos como a Antropologia Urbana, do Gênero, da Performance, dos Estudos Pós-coloniais e mesmo da Teoria Antropológica para repensar o cinema não apenas como modo de produção etnográfica, mas principalmente como objeto de pesquisa e como sujeito de nossos estudos; não apenas passivo ao nosso olhar, mas agente nas relações de sentido em que se engajam os sujeitos e coletivos do contemporâneo. Estamos aqui buscando caminhos ainda pouco trilhados, mas nem um pouco virgens. A discussão não é nova e está presente desde a aurora do cinema, entre seus críticos e teóricos (XAVIER, 1983: 9-15), mas pouco rendeu para a antropologia, além da crítica pós-moderna e feminista (MARCUS e FISCHER, 1986; CLIFFORD e MARCUS, 1986; HARAWAY, 1985; STRATHERN, 2004), que reconheceram a natureza autoral do trabalho etnográfico colocando-o em pé de igualdade às obras ficcionais realistas.

Para esse exercício, parto do trabalho de campo para a tese em Antropologia, realizada sobre o Festival Mix Brasil de Cinema da Diversidade Sexual, realizado em São Paulo desde 1993. Os festivais de cinema que têm em sua temática as questões de gênero e da "diversidade sexual" tornam-se interessantes para pensar possibilidade de construção de mundos possíveis. Quer da perspectiva do público, quer da perspectiva dos produtores, filmes apresentados nestes festivais de cinema se inserem dentro de um projeto de questionamento do cinema tradicional ou comercial que teria negado visibilidade a uma parcela de seu público (ZIELINSKI, 2006; LOIST, 2013). Bessa (2007), que tem estudado os festivais de cinema GLBT, considera:

Em geral, os festivais dessa natureza priorizam películas sensíveis a questões como AIDS, discriminação, solidão e desafios e dificuldades de se "assumir" uma 


\begin{abstract}
identidade gay, bem como reserva parte do repertório de exibição para filmes com forte conteúdo erótico. (...) Um dos pontos de partida do circuito de festivais GLBT, nos anos 1990, é o fato de serem primeiramente constituídos e constituintes de práticas representacionais que visam tornar presente, de modo positivo, imagens (função de mimeses, muitas vezes espelhada; noutras, autocrítica e bem humorada) relativas ao universo "homo" e seus arredores. (BESSA, 2007: 260)
\end{abstract}

Nas últimas décadas, o cinema mundial tem contado com estas produções e com estes festivais que dialogam com as políticas de representação que marcam as movimentações LGBTs desde os anos 60. Uma política que tenta liberar gays, lésbicas, bissexuais e travestis de estereótipos danosos (HANSON, 1999: 5) e pretende oferecer a essas relações uma feição diferenciada do cinema convencional hollywoodiano ou brasileiro, em que estas experiências foram reduzidas a estereótipos (RUSSO, 1987; MORENO, 2002). Podem enfocar as relações de mesmo sexo como elemento central das narrativas, para apresentar imagens positivas, românticas, sensuais e mesmo eróticas, dando a essas relações o que lhes fora negado na cinematografia tradicional ${ }^{2}$. Não deixam de incorrer, no entanto, na possibilidade de "normalização" ou domesticação, o que também tem gerado uma série de críticas (DEAN, 2007: 367). Talvez fosse interessante pensar o quanto esses discursos fílmicos não são apenas representações mas figuram nas formas de construção das relações de mesmo sexo, ao lado da cultura LGBT urbana, das organizações políticas e dos estudos gays e lésbicos.

São filmes que supostamente representam desde culturas da margem a situações nada marginais e trazem bases factuais implícitas, fazendo uso de um "realismo progressista" (SHOHAT e STAM, 2006: 264) para combater uma imagem hegemônica construída sobre os indivíduos e grupos marginalizados. São peças artísticas produzidas de uma perspectiva "de dentro", e que foram desde sempre o principal alvo dos curadores e programadores dos festivais desse tipo. Uma intenção que não está livre de problemas, pois a "realidade" e a "verdade" não são imediatamente apreensíveis por uma câmera (idem: 264). Neste sentido, poderíamos enumerar aqui uma série de exclusões que estes filmes promovem, retratando na tela situações que não representam a totalidade de experiências possíveis para homens e mulheres que se relacionam afetiva e sexualmente com outras de mesmo sexo. Porém, não se pode deixar de considerar que mesmo com tais limitações, esta cinematografia tem papel importante ao também gerar inversões no cinema convencional, ao fazer das territorialidades e temporalidades gays, lésbicas e transgêneros mundos possíveis.

Pensar no caráter construído do trabalho antropológico e dos mundos produzidos pelo cinema não significa instituir uma oposição entre eles e uma dada realidade, como se esta estivesse lá fora passiva ao nosso olhar e ao mesmo tempo inacessível em toda a sua plenitude. Se existe um "mundo real", ele só tem sua existência possibilitada graças a essas construções. Não existe realidade anterior ao discurso que a constitui, seja este os enunciados que permeiam a vida cotidiana e as relações interpessoais e coletivas, seja este discurso um

${ }^{2}$ Making Love (dir.: Arthur Hiller, EUA, 1982) é considerado um dos primeiros filmes comerciais estadunidenses ou do "mainstream hollywoodiano" (DEAN, 2007), com um grande orçamento, a lidar com a homossexualidade para uma audiência de massa sem se utilizar dos estereótipos clássicos - ou melhor, talvez tenha investido na semelhança com estereótipos de heterossexualidade -, com direito a final feliz para o casal protagonista e com cenas que foram elogiadas pela ousadia na imprensa gay da época (RUSSO, 1987: 271-2). Na história, um homem recém-casado com uma mulher se apaixona por outro homem, gerando toda uma ordem de transtornos em seu casamento. Ele vivencia o problema de aceitação de sua "condição homossexual", enquanto sua esposa precisa lidar com o fato de ser "trocada" por um homem, vivenciando uma dupla decepção. 
trabalho científico como a etnografia, seja ele um produto artístico como o cinema. A negação dessa anterioridade do discurso em relação à realidade parece ser uma preocupação que une a filosofia contemporânea (BUTLER, 1993; DELEUZE e GUATTARI, 1980) a trabalhos mais recentes da teoria antropológica (INGOLD, 2000), abrindo possibilidades interessantes para se repensar dicotomias clássicas como cultura/natureza, corpo/mente e, por que não, real/ficção.

\section{A ideia de cultura e a construção de mundos na antropologia}

Pensar a antropologia em termos da construção de uma realidade implica, entre outras coisas, entender o trabalho etnográfico como a produção de uma nova realidade a partir de uma realidade bruta, em que a primeira não é uma representação ou simplificação, mas uma forma de construir e acessar a segunda. Nos anos 80, o chamado movimento pós-moderno sistematizou algumas das principais críticas ao trabalho naturalista dos antropólogos que construíram a disciplina desde sua aurora no século XIX. Por mais realista que seja a descrição, o trabalho etnográfico exibe enredo, argumento e implicações ideológicas (MARCUS e FISCHER, 1986: 12). As etnografias modernas também se utilizaram de estratégias literárias e até mesmo fílmicas para a reconstrução dos coletivos humanos estudados. Da mesma forma que a câmera faz um recorte do mundo na hora da filmagem ou da fotografia, "o antropólogo escolhe o que chama a sua atenção e o completa com uma elaboração descritiva e detalhada para informar seus leitores nos termos de sua própria cultura a cultura de outrem" (idem: 29).

Esse próprio conceito de cultura que permitiria pensar numa cultura trobriandesa, ou numa cultura bororo, em oposição à cultura do antropólogo, pensadas como unidades discretas que podem ser representadas em forma de etnografia, esse conceito precisou também ser repensado. Se nesse trabalho utilizo por vezes o termo cultura LGBT não é por acreditar que exista algo como uma linguagem ou uma visão de mundo compartilhada por homens e mulheres que vivenciam gênero e sexualidade para além de uma matriz heteronormativa (BUTLER, 1990). Cultura está sendo usada aqui como uma "invenção" antropológica nos termos de Roy Wagner, quando diz que a ideia de cultura é produzida pelo antropólogo através de uma "experiência de contraste" com aqueles que busca pesquisar:

\footnotetext{
É apenas mediante uma "invenção" dessa ordem que o sentido abstrato de cultura (e de muitos outros conceitos) pode ser apreendido, e é apenas por meio do contraste experienciado que sua própria cultura se torna "visível". No ato de inventar outra cultura, o antropólogo inventa a sua própria e acaba por reinventar a própria noção de cultura. (WAGNER, 1981: 31)
}

Ou ainda, esta ideia de cultura está mais próxima do conceito de Moore (1999: 11) para quem a antropologia contemporânea parece acenar com a noção de cultura não como consenso, mas como campo de luta e conflito, como "uma série de lugares de representação contestada e resistência em campos de poder". Desde que o conceito de cultura passou a ser forjado e lapidado em termos acadêmicos pelas ciências humanas - empreendimento que a antropologia tomou para si, no século XIX - sua proposta era a de oferecer uma contradição ou oposição a um pensamento determinista que ia buscar na geografia ou na 
biologia a diferença entre os povos. Com o termo cultura, foi possível jogar com as relações históricas e políticas que construíram essas diferenças, deixando os fatos biológicos ou "naturais" em segundo plano, ou não os tratando como construídos.

Os vários desenvolvimentos que o conceito de cultura experimentou durante o século XX foram de suma importância tanto para a criação ou solidificação de esta-dos-nações como o Brasil, ainda nos anos 20 e 30 . A noção de cultura também serviu para todo um questionamento que será colocado pelos movimentos sociais, a partir dos anos 60, principalmente os que passaram a ter na questão dos direitos civis dos negros, das mulheres e dos homossexuais a sua principal missão. Se foi possível a um país como o Brasil forjar um conceito de cultura brasileira que pôde, pelo menos em tese, fazer ver uma nação possível e não atrasada devido à "mistura de raças" (ORTIZ, 1998), também foi possível questionar a autoridade masculina, branca e heterossexual num mundo que começava a questionar os grandes valores e as grandes narrativas. Ou seja, cultura torna-se sinônimo não de uma natureza irretocável mas a uma realidade construída e por isso mesmo passível de reconstrução.

Mas enquanto nessa época o conceito de cultura antropológico se populariza, na própria academia ele começa ser alvo de grandes questionamentos. A antropologia de Clifford Geertz (1973: 15) e a ideia um ser humano "amarrado em teias de significados que ele mesmo teceu" -, talvez represente o início dessa virada para além de um conceito de cultura menos determinista. Mais do que "algo que se tem", mais do que um conjunto de características que podem representar um grupo ou um povo, cultura nestes desenvolvimentos teóricos mais recentes começou a ser pensada em sua emergência, "algo que se produz", de onde surgem metodologias que vão ressaltar a qualidade emergente da cultura, como os estudos de performance, uma das principais contribuições dessa antropologia (BARBER, 2007). Significa dizer que "não há script para a vida social e cultural" (INGOLD; HALLAM, 2007: 1) ou, melhor, que a cultura não é uma série de instruções que os seres humanos precisam dominar para viver em grupo. Antes, há todo um processo de "criatividade" e "improvisação" que não são a exceção - como muitas vezes as ciências humanas colocaram estes temas - mas sim a regra de todo processo social e cultural ${ }^{3}$. Muitos estudos antropológicos tendem a criar uma falsa unidade entre grupos, a partir de uma ideia de cultura como algo compartilhado nas relações e não como produzido nelas.

Significa também pensar num "mundo em formação", em constante criação, mais "always in the making" (idem: 3), do que "ready-made", já pronto, um mundo em sua forma acabada. Cultura, neste enfoque, torna-se nada mais que um conjunto de possibilidades interpretativas a partir das experiências passadas. Os autores se utilizam das ideias de Edward Bruner para quem as pessoas criam cultura no processo de relação com as próprias contingências da vida (idem: 2):

Nesse processo eles são compelidos a improvisar, não porque eles estão operando pelo lado de dentro de um corpo estabelecido de convenção, mas porque nenhum sistema de códigos, regras e normas pode antecipar cada circunstância possível. No 
melhor pode prover guias gerais ou medições aproximadas cujo próprio poder está na vaguidão ou não especificidade. (Tradução livre)

A antropologia de Tim Ingold, a exemplo de outros contemporâneos, tem feito críticas a conceitos monolíticos como cultura e sociedade, por serem conceitos que podem pressupor o indivíduo em oposição ao social - uma das mais fortes heranças da sociologia durkheimiana - construindo sujeitos prévios às relações sociais das quais fazem parte. Ingold tem se utilizado de interessantes metáforas em seus questionamentos, como mapa (INGOLD, 2005a) e linhas (idem, 2007), que de forma simples e profunda oferecem uma nova visão sobre os indivíduos que não são atores num palco pronto, o mundo (idem: 107). Mundos e sujeitos estão sempre se construindo mutuamente.

O ambiente para Ingold, baseado numa abordagem ecológica, não é dado à priori nem é registrado num mapa mental, mas "é um terreno variado de idas e vindas que se forma continuamente em torno do viajante" (INGOLD, 2005a: 82). Trata-se de um "processo complexo" em que a ação e a percepção no ambiente se fazem a partir de experiências anteriores mas também de um "monitoramento contínuo do entorno". Nenhum mapa pode ser divorciado de suas condições de produção: "todo mapa está embutido em um "modo de vida" (idem: 84). Pensar a cultura como um mapa não indexável, ou seja independente dessas condições, equivale a pensar na sua transmissão na forma de um estoque na cabeça das pessoas, utilizado de acordo com as necessidades. O mapa, para Ingold, ou a representação espacial que se constrói só faz sentido na medida em que incorpora os movimentos de idas e vindas e outros deslocamentos. É o que Ingold vai chamar de "visão regional" e não "local", quando o ambiente não é percebido a partir de um ponto de vista fixo, "acima e além do mundo", mas percebido de diferentes pontos em uma "trilha de observação", conceito que Ingold empresta da "abordagem ecológica da percepção visual" de James Gibson (idem: 85).

Por sua vez, a antropologia de Roy Wagner (1981), ao se apropriar da ideia de invenção, lançou o conceito de cultura para uma outra dimensão, muito mais voltada para a criação de mundos do que para a representação de realidades. As pessoas, os objetos, os fatos da vida não existem como elementos independentes das relações, "símbolos e pessoas existem em uma relação de mediação mútua", o que significa também dizer que as "realidades são o que fazemos delas e não o que elas fazem de nós" (idem: 23). A forma como Wagner coloca o conceito de "invenção da cultura" também desfaz a dicotomia entre antropólogos e nativos: tanto uns quanto os outros estão inventando a sua própria cultura e a cultura do outro de modo a poderem estabelecer relações. As relações, essas sim, são mais reais do que as próprias coisas em relação, pois é nelas que as culturas tornamse visíveis. "No ato de inventar outra cultura, o antropólogo inventa a sua própria e acaba por reinventar a própria noção de cultura" (idem: 31).

Na prática, porém, não significa uma espécie de "livre fantasia" (idem: 30), em que cada um inventa o que quiser. Para Wagner, trata-se de um processo que ocorre de forma objetiva, ao longo das experiências do antropólogo e do próprio nativo. Essa objetificação é também uma forma de diminuir a tensão com a diferença, da mesma forma que o xamã e o psicanalista querem controlar a fone de uma ansiedade objetificando-a. Um processo que não acontece do zero, uma vez que os significados de uma "outra cultura" são produzidos a partir dos significados da cultura daquele que observa, a partir do que já se sabe, ultrapassando os limites de suas próprias convenções. 
Se a cultura fosse uma 'coisa' absoluta, objetiva, 'aprender' uma cultura se daria da mesma forma para todas as pessoas, tanto nativos como forasteiros, tanto adultos como crianças. Mas as pessoas têm todo tipo de predisposições e inclinações, e a noção de cultura como uma entidade objetiva, inflexível, só pode ser útil como uma espécie de 'muleta' para auxiliar o antropólogo em sua invenção e entendimento. (WAGNER, 1981: 36)

É por conta disso que aposto na expressão cultura LGBT, que representa um recorte do pesquisador em relação a um conjunto de performances e territorialidades que não abrangem a vivência de todos os homens e mulheres em relações homoafetivas, mas a uma certa urbanidade ou conjunto de práticas urbanas - de espaço e de imagem - que se inscrevem numa cidade como São Paulo, onde realizei uma pesquisa de campo sobre o Festival Mix Brasil de Cinema da Diversidade Sexual. As práticas urbanas desses coletivos e suas produções imagéticas não representam uma certa realidade, elas constituem essa mesma realidade, estão produzindo um mundo que, por mais hostil, não lhes retira a possibilidade de também construí-lo, tornando-o habitável (INGOLD, 2000). Da mesma forma, o olhar etnográfico busca não a representação desse mundo, mas a possibilidade de torná-lo palpável nos limites da etnografia para um público leitor.

Assim, não significa pensar na cultura do outro em oposição à cultura do antropólogo, como fossem duas unidades distintas. Wagner se utiliza do termo "extensão analógica", uma vez que as alegorias produzidas pelos antropólogos ou mesmo por um artista são analogias que se estendem a partir de seus próprios universos e tornam-se "modelos" para a "interpretação e compreensão de nossos temas" (idem: 45). Ou ainda: "E porque a percepção e a compreensão dos outros só podem proceder mediante uma espécie de analogia, conhecendoos por meio de uma extensão do familiar" (idem: 61). Essa "extensão analógica" nunca é absoluta, uma vez que ela é sempre produto de "conexões parciais" (STRATHERN, 2004: 50). E E através dessas conexões e das metáforas que utilizamos que os elementos que estão sob nosso estudo possuem um "potencial de integração" formando uma "sociedade" ou "cultura" (idem: 9). Marilyn Strathern desenvolve seu argumento em favor de uma etnografia ciborgue, tomando a imagem desenvolvida por Donna Haraway como uma alternativa a conceitos demasiadamente integradores.

\footnotetext{
Um ciborgue é um organismo cibernético, um híbrido de máquina e organismo, uma criatura de realidade social e também uma criatura de ficção. Realidade social significa relações sociais vividas, significa nossa construção política mais importante, significa uma ficção capaz de mudar o mundo. (HARAWAY, 1985:36)
}

As reflexões destas duas antropólogas, a partir do feminismo, fazem pensar tanto na questão da produção etnográfica, sem deixar de lançar mão da reflexão sobre os movimentos sociais e identitários das últimas décadas, dentro dos quais podemos incluir os festivais e os filmes desse cinema da diversidade sexual. "De uma outra perspectiva, um mundo de ciborgues pode significar realidades sociais e corporais vividas, nas quais as pessoas não temam identidades permanentemente parciais e posições contraditórias" (idem: 46; grifos meus). Em seu Manifesto Ciborgue, de 1985, Haraway questiona, entre outros tópicos, alguns feminismos daquela época que, geralmente sediados nos países da Europa ou nos Estados Unidos, tendiam a produzir discursos unificadores que supunham representar todas as mulheres do mundo. Uma política ciborgue para Haraway precisa fugir dessas taxonomias que constituem 
"unidades típicas" e tornam-se elas mesmas formas de "policiar qualquer posição que se desvie da experiência oficial das mulheres" (idem: 50). Mas ela fala da possibilidade da constituição de uma "cultura de mulheres", baseada não num fato determinista (neste caso, o sexo), mas numa "consciência de oposição" que vai constituir, sim, unidades, mas uma unidade poético-política (pois vai das artes à prática acadêmica) que não reproduza a lógica da apropriação, da incorporação e da identificação taxonômica. Para Haraway (1985: 89):

(...) estamos escritas no jogo de um texto que não tem nenhuma leitura finalmente privilegiada e nem qualquer história de salvação. Isso faz com que nos reconheçamos como plenamente implicadas no mundo, libertando-nos da necessidade de enraizar a política na identidade, em partidos de vanguarda, na pureza e na maternidade. (grifos meus)

Nestes mesmos termos, Haraway fala da possibilidade de uma etnografia experimental que deve tomar o lugar dos sistemas integrados (idem: 61) e abrir para os antropólogos a possibilidade escritas ciborgues que neguem a integração massificada de sujeitos sob certas categorias representativas. Podemos definir alguns nós: o filme "gay", a plateia "lésbica", ou mesmo a cultura LGBT, mas eles não dão conta dos muitos caminhos percorridos, das diferentes linhas inscritas até que esses sujeitos e coisas chegassem ali. É por isso que aquilo que chamamos de cultura LGBT pode ser pensado como um ciborgue que acopla homens, mulheres, objetos, ruas, bairros inteiros, filmes, festivais, paradas gays, casas noturnas, interesses de cinéfilos, gostos musicais, produções audiovisuais, sem que essa cultura se torne representativa de ninguém. Ela nada mais é do que o esboço de um mapa, conexões parciais que tentam reproduzir movimentos, sem conseguir dar conta de muitos deles - e sem sofrer por isso.

Foi ao reconhecer o caráter necessariamente ficcional da fotografia e do audiovisual que a antropologia visual fez pensar sobre questões como reflexividade, dialogismo e autoridade narrativa pelo menos vinte anos antes dessa discussão pós-moderna que ronda a etnografia desde as últimas décadas do século XX (LUTKEHAUS e COOL, 1999: 437). A obra cinematográfica de Jean Rouch já na década de 1950 reconhecia o caráter construído, ficcional, das imagens captadas pelas câmeras, o que lhe permitiu extrapolar as fronteiras do gênero documentário. Assim, as imagens deixaram de ser tomadas como idênticas a uma suposta realidade e se tornam o material básico sobre o qual o cineasta constrói uma nova realidade que se justifica não por sua representação mas pelo que pode trazer de novo à reflexão sobre nós mesmos e não sobre um Outro exótico e distante. Enquanto cineasta, Rouch vai se alinhar ao pensamento que sempre reconheceu no cinema algo mais do que o registro de uma realidade dada, representação do que existe independente da câmera, mas como uma possibilidade de se criar algo novo que suplanta essa suposta realidade (PIAULT, 2001).

No lugar de uma voz que guia a narrativa através de um poder-saber científico (BERNARDET, 2003), essa antropologia fílmica vai evitar o encompassamento dos sujeitos em teorias prévias sobre eles, colocando em relação diferentes vozes (dialogismo), dando lugar a práticas produzidas por eles, não representativas de uma realidade cultural, mas surgidas do próprio encontro etnográfico (reflexividade), sendo este uma experiência compartilhada e as práticas filmadas uma negociação desse encontro de olhares (idem: 441). 


\section{A montagem e a construção de mundos no cinema}

Se a linguagem cinematográfica que temos hoje como dominante nas produções audiovisuais é herdeira de uma tradição que se confunde com a própria história de Hollywood como indústria, que tem como marco a obra do cineasta estadunidense D.W. Griffith, pai dos fundamentos básicos da montagem $^{4}$, outras linguagens também se tornaram possível. Enquanto esse cinema de força industrial e comercial vai ser basear na chamada montagemnarração ou uma "ordem lógica ou cronológica" em que os planos e sequências contam uma história e onde as ações e motivações são explicadas em termos de causas e efeitos, outras escolas de cinema desenvolveram a possibilidade de uma montagem-afeto em que essa inteligibilidade é colocada em segundo plano em relação a sentimentos particulares que podem ser produzidos pela justaposição de imagens e sons (PIAULT, 2001: 157). Numa, uma linguagem cinematográfica transparente cuja "impressão de realidade" parece ser seu maior trunfo (BERNARDET, 1980: 43-4); noutra, o reconhecimento de que a realidade está sendo construída - e não representada - pelo próprio cinema, o que restitui ao meio uma agência que vai além do mero registro.

De um lado, temos trabalhos considerados fundantes do filme etnográfico, Nanook of the North (dir. Robert Flaherty, Canadá, 1922) e Rituais e Festas Bororo (dir. Thomaz Reis, Brasil, 1916) que se utilizaram das técnicas narrativas e naturalistas do cinema norte-americano (BARBOSA e CUNHA, 2006: 23; JORDAN, 1995: 21). De outro, uma série de vanguardas que, contrárias a Hollywood, criaram as possibilidades mais criativas para o cinema, ao libertá-lo de sua dependência do real, oferecendo novas possibilidades ao gênero documentário, também não mais circunscrito apenas ao binômio registro e representação, caso de $O$ homem com a câmera (dir. Dziga Vertov, URSS, 1929). Marc-Henri Piault (2001), teórico da antropologia visual, vai defender que é nesta segunda vertente que se baseará a produção audiovisual etnográfica realizada a partir de Jean Rouch. Seja na inspiração de filmes da Vanguarda Russa dos anos 1920, seja a partir do Neorrealismo Italiano dos anos 1940, imagens e sons não representam uma suposta realidade, mas criam uma nova para uma boa parte dos filmes etnográficos, ainda que trabalhos realistas e focados na vertente da "linguagem transparente" sejam possíveis e não raros 5 .

E foram muitas as lições dessa segunda vertente. Maya Deren, cineasta norte-americana, participou, nos anos 1940 e 1950, da vanguarda cinematográfica dos Estados Unidos, numa clara oposição conceitual em relação

\footnotetext{
4 "Aos poucos, a linguagem cinematográfica foi se construindo e é provavelmente aos cineastas americanos que se deve a maior contribuição para a formação dessa linguagem cujas bases foram lançadas até mais ou menos 1915. Uma linguagem, evidentemente, não se desenvolve em abstrato, mas em função de um projeto. O projeto, mesmo que implícito, era contar estórias. O cinema tornava-se como que o herdeiro do folhetim do século XIX, que abastecia amplas camadas de leitores, e estava se preparando para se tornar o grande contador de estórias da primeira metade do século XX. A linguagem desenvolveu-se, portanto, para tornar o cinema apto a contar estórias; outras opções teriam sido possíveis, que o cinema desenvolvesse uma linguagem científica ou ensaística, mas foi a linguagem da ficção que predominou" (BERNARDET, 1980: 32-33).

5 Num trabalho anterior (SILVA, 2010), sugiro a possibilidade de se pensar em duas vertentes do documentário brasileiro: um modelo sociológico, conforme a definição de Bernardet (2003), mais interessado numa narrativa fechada e explicativa de fenômenos sociais; e um modelo etnográfico, presente em muitos trabalhos da antropologia visual e em obras de cineastas como Eduardo Coutinho. Neste segundo modelo, “o que se privilegia na tela são as narrativas de personagens que não são meros entrevistados. Trata-se de um tipo de documentário que busca enfatizar não o conteúdo das falas que possam revelar 'verdades' sobre o assunto tratado, mas as condições próprias de elaboração desses textos, como são articulados no sentido de constituírem os sujeitos que falam” (SILVA, 2010: 162).
} 
ao cinema produzido por Hollywood, o cinema clássico. Essa vanguarda se junta a outras como o Surrealismo franco-espanhol, a Vanguarda Russa, o Expressionismo Alemão, destaques como escolas de experimentação mas, sobretudo, de estudo da linguagem audiovisual. Elas vão explorar os fundamentos da montagem, mas explorando a imagem e o som (não restrito aos diálogos) como elementos fundamentais da linguagem cinematográfica. $\mathrm{O}$ texto de Deren (1960) parece resumir um pouco da filosofia de uma geração. Ainda que se trate de imagens produzidas de forma artística, o cinema possuiria, segundo Deren ([1960]2012: 134) um obstáculo à sua definição "enquanto uma forma criativa de arte - capaz de ação criativa em seus próprios termos”. Esse obstáculo seria seu caráter como "imagem latente", vinculada a uma indelével realidade.

A autora está falando de um momento específico da história do cinema, em que as artes plásticas estavam fazendo do cinema "pintura animada", dado o desenvolvimento dos usos da cor, a animação, que segundo ela subaproveitariam o potencial do cinema. A autora também faz críticas ao cinema falado que se tornou narrativo demais, desvalorizando as imagens enquanto linguagem. Deren pretende um cinema não subordinado às outras formas de arte, uma vez que:

\begin{abstract}
O cinema tem uma extraordinária abrangência de expressão. Tem em comum com as artes plásticas o fato de ser uma composição visual projetada numa superfície bidimensional; com a dança, por poder lidar com a composição do movimento; com o teatro, por criar uma intensidade dramática de eventos; com a música, por compor em ritmos e frases de tempo e ser acompanhado por canção e instrumento; com a poesia, por justapor imagens; com a literatura em geral, por abarcar em sua trilha sonora abstrações disponíveis apenas à linguagem. (DEREN, 1960: 136)
\end{abstract}

$\mathrm{O}$ termo imagem tem uma dupla origem que vem tanto da imitação (ou seja, ela imita/representa a realidade exterior) quanto da magia - ela constitui uma nova realidade (CAIUBY NOVAES, 2008: 455). Deren vai defender a ideia de "imagens mentais" para pensar as imagens produzidas pelo cinema, mais próximas da noção de magia que de imitação. Para a cineasta, toda imagem presume uma atividade mental, o que seria uma forma positiva de pensar o conceito de imagem, conceituá-la ativamente, como se constituindo na relação com a percepção e a memória para se materializar como uma experiência, ou seja, uma imagem incompleta por si só que ativa quem a observa na construção do sentido. A imagem nas artes plásticas emerge como realidade própria a partir do momento em que passa pela seletividade do artista que faz da realidade um conceito. "A pintura não é imagem e semelhança de um cavalo é a semelhança. Ela é a semelhança de um conceito mental que pode se assemelhar a um cavalo ou que pode, como na pintura abstrata, não ter nenhuma relação visível com qualquer objeto real". A realidade é filtrada pelos interesses do artista.

$\mathrm{Na}$ imagem fotográfica/cinematográfica, o objeto cria sua própria imagem por efeitos da luz que emana. Neste caso, a participação ou a mão do artista está em outro lugar, que não o da criação dos objetos em si. É desse bordejar entre uma imagem que não é criada pela arte, mas que também não é uma representação fiel de uma realidade, que a imagem fotográfica/cinematográfica ganha seu status. Deren ainda recupera as especificidades da imagem e seu poder de mostrar o que não é visível ao olhar costumeiro, como as ampliações de imagens, as acelerações de sequências, o efeito câmera lenta, as "funções revelatórias" da imagem cinematográfica (um voo de pássaro em lentidão, por exemplo), exclusivas do meio audiovisual. 
Esta distinção desempenha um papel extremamente importante na abordagem dessas respectivas imagens. A proposta das artes plásticas é a de fazer com que o significado se manifeste. Ao criar uma imagem com o propósito expresso de comunicar, o artista basicamente se empenha em criar o aspecto mais eficaz possível a partir de todos os recursos do meio. A fotografia, entretanto, lida com uma realidade viva que é estruturada antes de mais nada para perdurar, e cujas configurações são designadas para servir a esse propósito, não para comunicar seu significado; elas podem até mesmo servir para ocultar esse propósito, como medida de proteção. Assim, numa fotografia, começamos com o reconhecimento de uma realidade, e nossos concomitantes conhecimentos e atitudes entram em ação; só então o aspecto se torna significativo em referência a ela. (DEREN, 1960: 139)

Ismail Xavier (2003) coloca a imagem cinematográfica no binômio revelação e engano que parece acompanhar a história do cinema: se por um lado, o cinema é "veículo para verdades" inatingíveis de outra forma - basta lembrarmos os exemplos de Maya Deren sobre as pesquisas científicas com imagens ou mesmo a Antropologia Visual e seu pendor para a documentação e observação do gesto humano e produção -, de outro, ele é o lugar de "simulação da verdade" - em que mundos podem ser construídos para além da própria realidade. Nos momentos de promessa (início do século XX) e nos de desencanto (anos 70-80) este debate vem à tona. (XAVIER, 2003: 31). A verdade está em cada pedaço da imagem, mas cada pedaço também pode não reter toda a verdade, construída num contexto maior. $O$ poder da imagem como evidência empírica, como documento, porque a função do recorte pode ou não ser ressaltada, enfocando ou não uma verdade produzida.

\begin{abstract}
Além da foto e de seu contexto, há que se inserir no jogo também o universo do observador e o tipo de pergunta que ele endereça à imagem. Ou seja, dentro de que situação se dá a leitura e ao longo de que eixo opõem-se verdade e mentira, revelação e engano. (...) Quando pergunto pela autenticidade de uma imagem, não estou, portanto, discutindo sua verdade em sentido absoluto, incondicionado. Não discuto a existência das figuras dadas ao olhar. Pergunto pela significação do que é dado a ver, numa interrogação cuja resposta mobiliza dois referenciais: o da foto (enquadre e moldura), que define um campo visível e seus limites, e o do observador, que define um campo de questões e seu estatuto, seu lugar na experiência individual e coletiva. (XAVIER, 2003:32-33)
\end{abstract}

Enquanto a imagem abstrata ganha seu significado a partir de aspectos que suscita, a foto/cinematográfica ganha este significado a partir do reconhecimento que aciona com seus aspectos "reais". Ela possui uma autoridade que vem dessa realidade, que fundamenta as produções de documentários. A realidade do filme, se fantástica ou realista, se imaginada ou já conhecida, ganha seu sentido de autoridade com a concretude de paisagens (ainda que sejam as maquetes de cidades e do espaço sideral que tornam "reais" muitos filmes). Os filmes tornam-se reais pela projeção de uma realidade que ensejam e não por serem fiéis a essa realidade:

\footnotetext{
O evento inventado então introduzido, mesmo que seja um artifício, empresta realidade da realidade da cena - do movimento dos cabelos, da irregularidade das ondas, da própria textura das pedras e da areia - em resumo, de todos os elementos espontâneos e fora de controle que são propriedade da própria realidade. Somente na fotografia - através da delicada manipulação que eu denomino acidente controlado pode o fenômeno natural ser incorporado à nossa própria criatividade, para produzir uma imagem em que a realidade de uma árvore confira sua verdade aos eventos que fazemos transpirar sob sua sombra. (DEREN, 1960: 141)
}

O cinema é uma arte que se constitui da própria realidade, enquanto as outras artes criam metáforas para ela. Metáforas para ideias e abstrações na fotografia são produzidas a partir desta mesma realidade, produzindo imagens 
arquetípicas, como com as personas do cinema (Greta Garbo, Charles Chaplin, cujas presenças ensejavam todo um mundo à sua volta, construído segundo tais arquétipos). Da mesma forma, os efeitos cinematográficos só conquistam sua verossimilhança por conta do mínimo de realidade que se consegue reter. O efeito dessas imagens se origina de nosso reconhecimento de uma realidade já conhecida.

Essa imagem, com sua habilidade única de nos engajar simultaneamente em diversos níveis - pela autoridade objetiva da realidade, pelos conhecimentos e valores com que atribuímos a essa realidade, pela comunicação direta de seu aspecto, e pela relação manipulada entre eles - essa imagem é o tijolo da construção criativa do meio. (Idem: 144)

Maya Deren sugere "abandonarmos o conceito de imagem como produto final e consumação do processo criativo (o que ela é, tanto nas artes visuais quanto no teatro)". No teatro e na pintura, a imagem é vista numa totalidade, enquanto o cinema se produz a partir de fragmentos mínimos de imagens que ganham sentido não de forma individual, mas na sequencialidade da montagem. A imagem de uma mesa bonita se desfaz na sequencia quando ela desmorona: os atributos da imagem são irrelevantes quando o que conta é a sua sequência:

\footnotetext{
Estejam as imagens relacionadas em termos de qualidades comuns ou contrastantes, na lógica causal dos eventos que é a narrativa, ou na lógica das ideias e emoções que é o modo poético, a estrutura de um filme é sequencial. A ação criativa no filme, portanto, ocorre em sua dimensão temporal; e por esta razão o cinema, muito embora composto por imagens espaciais, é basicamente uma forma de tempo. (Idem: 145)
}

Ela ainda cita oflashback, a ação paralela (conhecida também como montagem paralela), o quadro congelado, repetição de cenas, os travellings e panorâmicas que dão movimento a objetos inanimados. Pessoas podem ser colocadas juntas, estando em lugares separadas. Pode-se entrar pela porta e sair em um lugar fantástico/inusitado. Manipulações de tempo e espaço marcam a linguagem audiovisual e são a estrutura orgânica do filme. A autora quer destacar as mudanças de percepção que o cinema propicia e finaliza chamando a atenção para as especificidades do cinema de onde emanará como arte plena:

\begin{abstract}
Se o cinema se destina a ocupar seu lugar entre as formas artísticas plenamente desenvolvidas, deve deixar de meramente registrar realidades que não devem nada de sua existência ao instrumento fílmico. Pelo contrário, deve criar uma experiência total, oriunda da própria natureza do instrumento a ponto de ser inseparável de seus próprios recursos. Deve renunciar às disciplinas narrativas que emprestou da literatura e sua tímida imitação da lógica causal dos enredos narrativos, uma forma que floresceu como celebração do conceito terreno e paulatino de tempo, espaço e relação que foi parte do materialismo primitivo do século XIX. Pelo contrário, deve desenvolver o vocabulário de imagens fílmicas e amadurecer a sintaxe de técnicas fílmicas que as relaciona. Deve determinar as disciplinas inerentes ao meio, descobrir seus próprios modos estruturais, explorar os novos campos e dimensões acessíveis a ele e assim enriquecer artisticamente nossa cultura, como a ciência o fez em seu próprio domínio. (Idem: 149)
\end{abstract}

A ideia do cinema como produtor de uma narrativa, através do uso criativo da realidade, nos leva a pensar a antropologia, nos mesmos termos, tal como já o fizeram os pós-modernos, as feministas e outros críticos ao enquadrarem a etnografia como uma alegoria (CLIFFORD, 1997), autoral (GEERTZ, 1988), ciborgue (HARAWAY, 1985), ficção persuasiva (STRATHERN, 1987), evocativa (TYLER, 1986), contaminada (STEWART, 1991). Ou seja, a antropologia também se utiliza de fragmentos de realidade, impossível de ser totalizada, e é no arranjo desses fragmentos, tal qual na montagem cinematográfica, que nós 
construímos nossos conhecimentos, na justaposição/conexão entre personagens distantes no tempo e no espaço, na sequencialidade entre ações que passa a construir um sistema narrativo entre as mesmas, em nossas descrições densas e narrativas que partilham das mesmas fontes da narrativa cinematográfica, dando sentido a uma profusão de sons e imagens que por si só não retém todos os sentidos e significados. Na polifonia das imagens, é a sequência que vai construir o sentido do filme, da mesma forma que a antropologia encontra na produção da etnografia a organização de uma polifonia semelhante.

A ligação que estou propondo aqui entre o cinema e a antropologia como produtores de mundos a partir de fragmentos da realidade pode parecer estranha quando pensamos nos filmes que fazem parte da história da antropologia, que sempre se ligaram mais à ideia de documentário do que de ficção. As primeiras produções cinematográficas eram também mais ligadas a uma representação do real. Desde a invenção do cinematógrafo, as chamadas "vistas" buscavam retratar, sem narrativa, tanto cenas do cotidiano das cidades da Europa quanto povos supostamente distantes, como os ashanti, filmados pelos irmãos Lumière e exibidos numa exposição em Paris em 1897 (PIAULT, 1995), no que se tornou o primeira registro de africanos em cena, ainda que estivessem na França (JORDAN, 1995: 20). Ou seja, os primeiros filmes eram de caráter etnológico, tinham uma preocupação de apresentar o "outro" para os europeus, além de tornar os próprios europeus "outros" de si mesmos. Viraram as câmeras para si mesmos e fizeram de seus próprios cotidianos algo observável através de uma câmera filmadora. Se a aldeia ashanti era uma novidade, o mesmo não pode ser dito de um trem chegando à estação, algo corriqueiro mas que causou espanto em sua projeção num café em Paris, em 1895, na primeira exibição pública promovida pelos Lumière (BERNARDET, 1980: 12). Assim, imagens do cotidiano se mesclavam com imagens de povos distantes, numa tipo de educação do olhar que sempre acompanhou a história do cinema, tornando visto, olhável e apreciável o que disfrutara até então de invisibilidade absoluta ou relativa.

Da mesma forma e compartilhando da mesma contemporaneidade, a modernidade da virada dos séculos XIX para XX, a antropologia também se constituiu como um olhar produzido do Ocidente para focar suas lentes tanto no distante quanto no próximo (ainda que este segundo movimento tenha sido mais demorado). Mas se o cinema logo encontraria o caminho da arte com George Méliès, a antropologia só recentemente passaria a assumir a sua condição autoral. Talvez tenhamos que fazer como sugere Maya Deren e aproveitarmos o potencial criativo das produções etnográficas, ao construir e repensar criticamente os mundos e a história. Assim, uma primeira conclusão dessa discussão, é a de que talvez possamos enquanto antropólogos nos libertarmos das amarras do trabalho canônico - seja a etnografia naturalista moderna, seja a escrita pós-moderna - e darmos espaço a outras possibilidades de experimentação.

No cinema, as relações entre visível e invisível, a interação entre o dado imediato e sua significação, tornam-se mais intrincadas. A sucessão de imagens criada pela montagem produz relações novas a todo instante e somos sempre levados a estabelecer ligações propriamente não existentes na tela. A montagem sugere, nós deduzimos. (DEREN, 1960: 33)

O cinema possui uma liberdade invejável de contextualizar. A Vanguarda Russa partia do pressuposto máximo da montagem em que é a sequência que 
constrói o sentido e não a imagem isolada. O espectador aceita o jogo de faz-deconta e não dirige perguntas sobre legitimidade e autenticidade, "o essencial é a imagem ser convincente dentro dos propósitos do filme que procura instaurar um mundo imaginário" (XAVIER, 2003: 34). Cidades e corpos são criados a partir de fragmentos de cidades e corpos. Ações e reações criam um fato que só existe na tela. Aceitar tais fatos é entrar no jogo e não romper o pacto firmado na sala de cinema.

\begin{abstract}
Para iludir, convencer, é necessário competência, e faz parte dessa saber antecipar com precisão a moldura do observador, as circunstâncias da recepção da imagem, os códigos em jogo. Embora pareça, a leitura da imagem não é imediata. Ela resulta de um processo em que intervêm não só as mediações que estão na esfera do olhar que produz a imagem, mas também aquelas presentes na esfera do olhar que as recebe. Este não é inerte, pois, armado, participa do jogo. (XAVIER, 2003: 35)
\end{abstract}

Tim Ingold (2005b) tem um argumento semelhante em seus estudos sobre a percepção do ambiente, ao defender que as paisagens não são observadas de pontos-de-vista, mas de trilhas-de-vista, em que diferentes posições constituem ângulos e relações que fazem ver a paisagem que nunca está apenas lá, dada ao olhar, passiva e na espera de ser vista. Volto neste ponto mais adiante.

\title{
Por uma antropologia do cinema: a etnografia de um festival de filmes da diversidade sexual
}

Um festival de cinema para o trabalho etnográfico suscita inúmeras possibilidades que não estão desconectadas da discussão anterior sobre a antropologia visual e vão desde a antropologia da performance - uma vez que festivais e filmes estão dentro dos chamados eventos liminoides que marcam os rituais e festividades das sociedades modernas (TURNER, 1982; STOELTJE, 1992: 261) -, passam por uma antropologia urbana - considerando que tais festivais marcam a urbanidade do século XX, sendo um campo fértil para se pensar as relações entre cinema e cidade (SILVA, 2013) - e podem nos levar a campos como das antropologias do gênero e da sexualidade - já que neste caso específico trata-se de um festival de cinema cujo tema de seus filmes e debates são pautas das movimentações LGBTs, gays e lésbicas, queers, das últimas décadas. Há também pontos que sempre preocuparam as teorias do cinema e que podem movimentar temas bastante caros à teoria antropológica contemporânea.

Discutir "as ações do aparato que constrói o olhar no cinema” (XAVIER, 2003: 35) - uma tarefa da Teoria do Cinema que pode ser apropriada pela antropologia - significa, entre outras coisas pensar o olhar do cinema como mediação. A partir de uma identificação entre o olhar do espectador e o olhar da câmera, o jogo no qual o espectador entra, o principal e mais genérico, é aquele em que há "um forte sentimento de presença do mundo emoldurado na tela, simultâneo ao meu saber de sua ausência (trata-se de imagens, e não das próprias coisas)" (idem: 35). Há um olhar anterior ao do espectador que organiza - apesar de não determinar - aquele mundo pra ele, se interpondo. São dois olhares que não se confundem: o encontro câmera/objeto e o encontro espectador/cinematógrafo na sala do cinema. O olhar anterior (câmera/objeto) se pauta por escolhas que estão ausentes no segundo (espectador/ cinematógrafo), como a perspectiva de observação, a possibilidade de se mexer e buscar diferentes posições diante do real. "Espectador de cinema, tenho meus 
privilégios. Mas simultaneamente algo me é roubado: o privilegio da escolha" (idem: 36 ).

Festivais, disciplinas científicas e identidades guardam entre si inúmeras semelhanças das quais algumas parecem se destacar, principalmente se as tomarmos pelos seus princípios performáticos, que parecem estabilizar, ao mesmo tempo em que colocam em relevo, as suas contradições. Um festival de cinema como o Mix Brasil apresenta a estabilidade de uma ideia de cinema sublinhando todos os seus títulos com base num conceito de diversidade sexual. Mas as próprias histórias desses filmes, tomados isoladamente, não necessariamente apostam nesse mesmo ideal. De forma parecida, um determinado recorte teórico muitas vezes pode representar a estabilidade para o cientista social ou, mais que isso, uma forma de controlar e impor estabilidade a elementos e fenômenos que, se deixados "livres", não param de estabelecer e de desfazer conexões.

$\mathrm{Na}$ pesquisa para a tese de doutorado, tentei iluminar algumas dessas conexões, pelo menos as que me pareceram mais evidentes. Em primeiro lugar, foi preciso pensar no cinema, em geral, e nos festivais, em particular, como experiências citadinas e da modernidade (LARKIN, 2002), o que foi narrado através dos próprios caminhos da etnografia, das conexões que o festival estabelece com as "manchas gays" da cidade (FRANÇA, 2006) e dos próprios filmes que estabelecem um vibrante diálogo com a urbanidade contemporânea, o que fez de São Paulo uma importante personagem da pesquisa (SILVA, 2013). Num segundo momento deste trabalho, foi através de sua estrutura, sua programação e seus filmes que o Mix Brasil foi tomado, o que foi também uma forma de pensar em outras relações que o festival estabelece, mas através de suas cinematografias, que podem tanto seguir os supostos desejos de um público quanto surpreendê-lo.

Como um festival que por quase vinte anos tem exibido filmes e vídeos, de longa e curta-metragem, cujo tema central gira em torno da controversa ideia de "diversidade sexual”, o Mix Brasil tornou-se um território privilegiado de contato com um conjunto de filmes que tem sido lido como avesso a outros cinemas. Se um festival de cinema, por si só, se coloca como um espaço-tempo de exceção - como no caso dos festivais internacionais que exibem os principais lançamentos da indústria de cinema, antes de entrarem em circuito comercial -, um festival como o Mix se diferencia por trazer filmes marcados, obras que são lidas dentro de uma visão que contempla uma série de ensejos das políticas de representação ligadas às movimentações LGBT das últimas décadas. São filmes que talvez tenham outras leituras em outros territórios, em que não sejam classificados como gays, lésbicos, queers ou da diversidade sexual, mas aqui é dentro desse olhar que essas produções são apropriadas, um movimento que permitiu pensar o quanto os filmes continuam sendo produzidos, através dessas releituras e dessas exibições.

Realizado desde 1993, na esteira de outras manifestações que tematizaram a diversidade sexual nos anos 80 e 90, o Mix Brasil se consolida como um dos territórios de São Paulo que, nas últimas décadas, performa essas preocupações. Mas o festival também precisa ser lido pelas conexões que tem estabelecido, desde a primeira hora, com os artistas visuais baseados em São Paulo, sem deixar de se conectar com uma rede maior de entretenimento na cidade, como circuitos de cinema, salas de teatro e centros culturais. Exibindo e colocando em competição trabalhos que vão de formatos profissionais a produções amadoras, 
o Mix Brasil reúne produções dos mais variados lugares do mundo em que se produz cinema, organiza retrospectivas que recuperam títulos com a presença sempre contestada de personagens não heterocentrados, e constitui uma mostra competitiva que todos os anos sugere a reunião do que de melhor em "diversidade sexual" foi produzida no audiovisual brasileiro de curta-metragem.

Além disso, produziu eventos especiais como o Show do Gongo, um festival dentro do Mix, que é ao mesmo tempo uma antítese dele e uma de suas noites mais representativas, ao trazer à tona vídeos e um tipo de competição que podem ser lidos como uma performance parodística do próprio Mix Brasil, promovendo o "destronamento" (BAKHTIN, 1987) das "imagens positivas" que marcam outras sessões do festival. Há também eventos que não são ligados diretamente ao cinema, mas que fazem conexão com o Mix através da ideia de diversidade sexual, como o Mix Music, que trouxe à programação artistas da "música alternativa" de São Paulo e outros que foram apropriados pela "cultura gay" da cidade - como cantoras de música romântica dos anos 80 -, e o Dramática, que colocou em cena leituras e montagens teatrais de textos consagrados, também lidos nesse contexto através da ideia de "diversidade sexual”. O Mix Brasil tornou-se assim um território visível no espaço e no tempo, um nó de conexões parciais (STRATHERN, 2004), uma superfície para a qual convergem várias linhas (INGOLD, 2007), em que um conjunto de performances permite que filmes, festivais, sexualidades e identidades sejam vistas.

O cinema e sua tradição, um festival e sua programação, um filme e seus 90 minutos são idealizações, imagens estabilizadas dentro de um emaranhado incontrolável de intensidades que, mudando as conexões, pode levar a novas interpretações do que seja cada um deles. A reunião dos filmes na programação de um festival ou de uma mostra temática se faz de forma performativa, um conjunto de estratégias discursivas que estabilizam e naturalizam essa classificação. Por mais que pareça fácil aceitar uma lista de filmes em mostras que tematizam a diversidade sexual, eles também precisam de explicações adicionais, ou melhor dizendo, um agenciamento que faz com que sejam percebidos "naturalmente" dentro daquela categorização.

Se os festivais geram suas expectativas sobre os filmes e sobre um público espectador (RASTEGAR, 2009), o público também constrói filmes com suas expectativas e com as imagens que entram nesta relação. Para tanto, foi preciso considerar que os filmes se fazem por um processo que engloba muito mais do que o processo de realização e distribuição da película, e começa desde as falas sobre o filme na mídia, passa pelas imagens que são "contrabandeadas" pela internet e vai ganhando corpo nas imagens de divulgação dos cartazes, nos trailers, num longo caminho que faz com que aquele espectador - salvo raras exceções - já tenha começado a assistir o filme antes de entrar na sala de cinema ou quando ainda está na locadora lendo as informações da capa. O filme que estreou a noite de abertura do Mix no ano dessa pesquisa, Do Começo ao Fìm (dir. Aluízio Abranches, Brasil, 2009), começou sua carreira quase um ano antes de sua estreia nacional, de forma tímida, quando os jornais davam conta do novo filme do cineasta, sobre uma "delicada relação" de amor entre dois meios-irmãos. Mas foi quando as imagens de divulgação começaram a circular pela internet, em abril de 2009, que o filme começou a ganhar contorno e substância. O trailer que circulava tinha em torno de cinco minutos, bem mais que os trailers comuns de divulgação, quase um curta-metragem que, em duas 
semanas, atingiu um milhão de acessos ou exibições na internet. Nos comentários feitos pelos espectadores nos sites em que esse trailer foi exibido, era de que se tratava do Brokeback Mountain ${ }^{6}$ (dir. Ang Lee, EUA, 1995) brasileiro e representava uma "evolução" no cinema nacional. Essas leituras contribuíram para que o filme fosse o primeiro longa-metragem brasileiro a abrir uma edição do Mix.

Assim, há também todo um processo anterior que expande a produção do festival para além do próprio período e espaço de organização. Talvez seja possível afirmar que a experiência do cinema proporciona a cada espectador um contato com uma narrativa, através de sons e imagens, um fluxo sensorial que as teorias da performance muito bem nos situam. Por outro lado, a experiência de cada espectador parte desse fluxo oferecido pelo filme e se espraia por uma série de outras conexões que vão depender de histórias de vida e visões de mundo, fazendo com que o tempo limitado do filme torne-se uma experiência expandida. Ao sair da sala de cinema ou mudar de canal/desligar a tevê ou o microcomputador, aquela experiência pode cessar ou se reverberar pelas atividades que compõem a vida de cada sujeito.

Em seus escritos antropológicos mais recentes, Tim Ingold (2005a, 2005b, 2011) elabora uma teorização que nos permite pensar em festivais, filmes, imagens e no "visual", de uma forma geral, não como aquilo que existe à espera do olhar e independente das condições desse olhar. Para o autor, o visual é o que "pode ser visto", que pode "tornar-se visível", a partir de um jogo muito parecido com o visto acima entre enunciados e visibilidades. Mas em vez de enunciados, Ingold investe na ideia de envolvimento no ambiente, em que "ver" torna-se uma "experiência de luz" e não mero registro de um ambiente exterior ao ser. "Ver" torna-se "poder ver" sob certas condições de um ambiente que nos afeta $^{7}$ com sua luminosidade:

\begin{abstract}
Eu não me sinto imerso no mundo em um momento e, em seguida, colocado contra ele. No entanto, eu tenho um sentimento poderoso que por trás do meu reconhecimento de vários tipos de objetos e superfícies, tais como as pedras da praia e as ondas do mar, lá há a experiência de habitar um mundo iluminado, e que essa iluminação era de alguma forma constitutiva da minha própria capacidade de ver. A implicação é que, conforme o tempo muda, não vemos coisas diferentes, mas vemos as mesmas coisas de forma diferente. (INGOLD, 2005b: 102, grifos do autor; tradução livre)
\end{abstract}

O autor parte do exemplo da observação de uma paisagem, que geralmente é pensada como que independente das condições de luminosidade que permitem vê-la. Para ele, o fato de que o próprio tempo (weather) modifica o que "pode ser visto" da paisagem, traz para o foco da percepção o espaço intersticial entre o observador e a paisagem/imagem/objeto observado, através do qual essa paisagem não é apenas vista mas sentida de forma multissensorial. Assim, o vento, a chuva e as diferentes intensidades da luz ganham agência e constituem essa paisagem, não sendo meros elementos observáveis no quadro dessa imagem, mas como um veículo ou "meio de percepção" que a torna possível. A ideia é superar o cânone ocidental e a "imagem colonial" em que a vida se desenrola na superfície de "um mundo congelado em sua forma final",

\footnotetext{
${ }^{6}$ Brokeback Mountain foi recebido pela crítica e pelo público como o primeiro filme hollywoodiano a enfocar uma relação homoafetiva tendo destaque na indústria do cinema, concorrendo aos principais prêmios do Oscar naquele ano.

${ }_{7}$ Neste sentido, Ingold (2005b: 98) faz uma comparação entre as formas como os cânones ocidentais colocam o som e o visual na relação com os corpos, pois se é comum pensarmos nossos ouvidos como buracos por onde o som entra, no caso dos olhos eles geralmente são imaginados como telas que não deixam passar a luz, apenas registram-na para a formação de imagens cerebrais, o que faz o interior da cabeça barulhento mas escuro.
} 
para pensá-la no "meio de um mundo de fluxo perpétuo" (idem: 103), em que os indivíduos não estão numa relação de oposição, mas numa imersão que pode ser pensada para além de seus limites corporais e coerências identitárias.

Os estudos de gênero de Judith Butler (1990; 1993), apresentam uma preocupação semelhante ao que se refere à produção de sujeitos em corpos sexuados ou marcados por gênero. Ela recusa a anterioridade desses corpos e dos sujeitos à entrada em campos de saber e poder, através de uma discussão que revê também a distinção entre sexo e gênero, o primeiro tomado como "fato natural" e o segundo como interpretação cultural imposta sobre esta mesma natureza. Para Butler, os corpos e os sexos conquistam materialidade como "efeito sedimentado de uma prática reiterativa ou ritual", ou seja, o que nos permite ver corpos "de homens" e "de mulheres" é a entrada numa matriz heteronormativa, que reconhece e precisa da produtividade dessa di-visão, em que a materialização se estabiliza através do tempo na produção do "efeito de fronteira, fixidez e superfície". A heterossexualidade enquanto um regime, "opera para circunscrever e contornar a 'materialidade' do sexo, e essa 'materialidade' é formada e sustentada como uma materialização de normas regulatórias que são, em parte, aquelas da hegemonia heterossexual” (BUTLER, 1993: 9-10).

Guardadas as diferenças teóricas e de abordagem, a ideia das diferentes condições que constituem o olhar já foi tematizada ou colocada em prática pelos estudos de recepção e suas abordagens etnográficas nos anos 80 (JACKS, 2010; FACHEL LEAL, 1986), assim como pela teoria do cinema (ver AUMONT, 1995). Acredito, no entanto, que as contribuições de Ingold e de Butler vão além dessas possibilidades ao romper com a fronteira entre observador e observado, entre o sujeito que vê e a imagem que é vista, o que pode trazer contribuições interessantes para a pesquisa em cinema e festivais. A visão, o "ver", não são ações de registro do entorno ou observação do mundo para que os indivíduos, de posse das informações resultantes, possam planejar suas atividades. São, antes, formas de engajamento e envolvimento com um mundo em produção, em que o visível se constitui não apenas através do olhar, mas de todo o corpo.

Pensar a visão nestes termos traz uma outra possibilidade de se pensar a recepção do cinema que, em muitas teorias, foi pensada dentro da lógica do "olhar sem corpo" (XAVIER, 2003: 45), que seria uma estratégia da linguagem cinematográfica em naturalizar-se e ser tomada como representação do real, ao rejeitar qualquer forma de engajamento que não seja a do olhar do espectador, restrito a contemplador visual de um mundo já pronto. É nele, mais do que em qualquer outra proposta, que vemos realizado o projeto de intensificar ao extremo nossa relação com o mundo-objeto, fazer tal mundo parecer autônomo, existente em seu próprio direito, não encorajando perguntas na direção do próprio olhar mediador [o olho da câmera e do cineasta], sua estrutura e comportamento. Somos aí convidados a tomar o "olhar sem corpo" como dado natural. (idem: 45).

Ainda que não seja possível descartar essa possibilidade de apreensão de um filme, seria complicado pensarmos nas sessões de filmes e vídeos que compõem um festival de cinema - essa formação territorial que se projeta como um "meio de percepção" (INGOLD, 2005b: 102) - como momentos individualizados, em que cada espectador, "desligado do mundo lá fora”, entra numa viagem individual através de um elo com um "mundo de sonhos" (VEIGA, 1998: 33). A experiência dos festivais, como territórios complexos ou como 
platôs onde vibram várias intensidades (DELEUZE e GUATTARI, 1980), traz o corpo para o olhar que sozinho não é capaz de "registrar" a complexidade dessa experiência, marcada por intensificações e deslocamentos. Essa possível ligação com um "mundo de sonhos", principalmente em eventos marcados como um festival de cinema, não necessariamente exige a suspensão do entorno, tampouco restringe o espectador à ligação com o espaço retangular da grande tela à frente da plateia.

Se o assistir a um filme pode ser pensado como uma experiência multissensorial, festivais como o Mix Brasil nos permitem pensar nesses eventos como uma superlativação dessa multissensorialidade. São componentes complexos desse "poder ver" filmes: a experiência de assistir coletivamente um filme - há tempos não mais hegemônica nos usos do cinema -, as possíveis paqueras na sala de exibição ou no hall de entrada, a presença na plateia de um ator que também está na tela, um diretor ou curador de festival que abre uma sessão de curtas, um debate após a projeção, exibições em bairros e salas que têm suas histórias, ou o trivial ato de circular pelo cinema com um catálogo do festival com suas imagens e textos que nos trazem os filmes em conjunto. Não cabe, no entanto, construir uma dualidade entre a recepção individual de filmes e a recepção coletiva que os festivais proporcionam, mas torna-se necessário pensar tanto numa como noutra como experiências rizomáticas (DELEUZE e GUATTARI, 1980) que podem até estabelecer uma ligação com um "mundo de sonhos", sem deixar de levar em conta o ambiente em que os indivíduos estão imersos materializando seus corpos através de um emaranhado que os conecta à grande tela, às experiências urbanas e aos discursos contemporâneos artísticos e políticos sobre gênero e sexualidade - experiências e discursos que no mesmo processo se constituem.

Assim foi preciso pensar o Mix Brasil enquanto formação territorial em construção constante, da mesma forma que os filmes e os sujeitos não param de produzir-se. Nesse sentido, a etnografia do optou por dois caminhos teóricos, como a performance e a territorialidade, colocando em evidência, ou tornando visíveis as várias práticas de territorialização que se dão a partir de um festival de cinema como o Mix Brasil. A territorialização é um processo que não cessa, pois o que ela produz depende dessa continuidade produtora (DELEUZE e GUATTARI, 1976). Assim, um festival de cinema produz inúmeros processos de reterritorialização e se abastece de outros processos em devir. Conectando-se ao contemporâneo das grandes capitais do mundo, ao mesmo tempo em que se espraia por territorialidades locais - como as "manchas gays" ou com os "circuitos de cinema de arte" -, o Mix Brasil une várias pontas de processos que tem se constituído na modernidade, principalmente no que se refere às questões que englobam os campos dos gêneros e sexualidades. É como um festival de cinema LGBT, queer ou dentro da rede dos festivais gays e lésbicos (LOIST, 2013), que o Mix tem sido reconhecido por mais de duas décadas. Mas ele também aponta para as muitas faces do audiovisual brasileiro, tanto em suas estratégias estéticas e de produção autoral, quanto no contexto de um cinema brasileiro praticamente marginalizado em seu próprio país.

As próprias movimentações LGBTs urbanas que citei não são passivas neste jogo, não estão apenas reagindo, mas também reivindicam o direito de produção dessas sexualidades. Constituem novos discursos, novos territórios, novas imagens que colocam em xeque, muitas vezes, a hegemonia dos discursos religiosos e biomédicos, denunciando-os como falas localizadas que podem ser 
refeitas ou repensadas. Inventam, assim, mundos considerados possíveis para estes sujeitos. Uma invenção que precisa ser pensada não como um acidente, mas como um "componente positivo e esperado da vida humana" (WAGNER, [1981] 2010:19). Se toda uma "cultura sexual" pôde ser inventada no Ocidente moderno (FOUCAULT, 1976), tal fato também ofereceu espaço para a formação de uma cultura LGBT que mais uma vez está sendo inventada pelo antropólogo em sua abordagem nesta pesquisa.

\section{Referências}

ALENCAR; Eunice; FLEITH, Denise. Contribuições teóricas recentes ao estudo da criatividade. Psicologia: Teoria e Pesquisa, 19(1). Brasília, UnB, 2003. p. 1-8.

AUMONT, Jacques. A imagem. $2^{\text {a }}$ ed. Campinas, Papirus Ed., 1995.

BAKHTIN, Mikhail. A Cultura Popular na Idade Média e no Renascimento: o contexto de François Rabelais. São Paulo, EdUnB/Hucitec, 1987.

BARBER, Karin. "Improvisation and the Art of Making Things Stick". In: HALLAM, E.; INGOLD, T. (eds.). Creativity and Cultural Improvisation. Oxford/New York, Berg, 2007. p. 25-41.

BARBOSA, Andréa; CUNHA, Edgar Teodoro da. Antropologia e Imagem. Rio de Janeiro, Jorge Zahar Ed., 2006.

BERNARDET, Jean Claude. "O modelo sociológico ou a voz do dono". In: Cineastas e imagens do povo. São Paulo, Ed. Brasiliense, 2003.

BERNARDET, Jean Claude. O que é cinema. Coleção Primeiros Passos (9). São Paulo, Brasiliense, 1980.

BESSA, Karla. Os festivais GLBT de cinema e as mudanças estético-políticas na constituição da subjetividade. Cadernos Pagu (28), janeiro-junho, 2007. p. 257283 .

BUTLER, Judith. Bodies that matter: on the discursive limits of "sex". Nova York e Londres, Routledge, 1993.

BUTLER, Judith. Problemas de Gênero. Rio de Janeiro, Civilização Brasileira, [1990] 2003.

CAIUBY NOVAES, Sylvia. Imagem, magia e imaginação: desafios ao texto antropológico. Mana, 14 (2). Rio de Janeiro, Museu Nacional/UFRJ, 2008.

CLIFFORD, James; GONÇALVES, José Reginaldo Santos (org). A Experiência Etnográfica: antropologia e literatura no século $X X$. Rio de Janeiro, Ed. UFRJ, 2002. p. 17-62.

CLIFFORD, James; MARCUS, George E. (eds.). Writing Culture: the Poetics and Politics of Ethnography. Berkeley, Univ. of California, 1986. 
DEAN, James Joseph. Gays and Queers: from the centering to the decentering of homosexuality in American films. Sexualities, 10(3), 2007. p. 363-386.

DELEUZE, Gilles; GUATTARI, Félix. Mil Platôs. Vol. 1. São Paulo, Editora 34, [1980] 1997.

DEREN, Maya. Cinema: o uso criativo da realidade. Devires, 9(1). Belo Horizonte, UFMG, [1960] 2012. p. 128-149.

FACHEL LEAL, Ondina. A leitura Social da Novela das Oito. Petrópolis, Vozes, 1986.

FOUCAULT, Michel. História da Sexualidade I: a vontade de saber. $17^{\mathrm{a}}$ edição. Rio de Janeiro, Graal, [1976] 2006.

FRANÇA, Isadora Lins. Cercas e pontes: o movimento GLBT e o mercado GLS na cidade de São Paulo. (Dissertação de Mestrado). São Paulo, PPGAS/USP, 2006.

GEERTZ, Clifford. A Interpretação das Culturas. Rio de Janeiro, LTC, [1973] 1989.

GEERTZ, Clifford. El antropólogo como autor. Barcelona, Paidós, 1997.

HALLAM, E.; INGOLD, T. "Creativity and Cultural Improvisation: an introduction". In: HALLAM, E.; INGOLD, T. (eds.). Creativity and Cultural Improvisation. Ox-ford/New York, Berg, 2007. p. 1-24.

HANSON, Ellis. "Introduction: Out Takes". In: HANSON, Ellis (org.). Out Takes: Essays on Queer Theory and Film. Durham e London, Duke University Press, 1999.

HARAWAY, Donna. "Manifesto ciborgue: ciência, tecnologia e feminismosocialista”. In: TADEU, Tomaz (org.). Antropologia do ciborgue: as vertigens do pós-humano. Belo Horizonte, Autêntica, [1985] 2009.

INGOLD, Tim. Being Alive: essays on movement, knowledge and description. London: Routledge, 2011. 270 p.

INGOLD, Tim. Jornada ao longo de um caminho de vida - mapas, descobridorcaminho e navegação. Religião e Sociedade, 25(1). Rio de Janeiro, ISER, 2005a. p. 76-110.

INGOLD, Tim. Lines: a brief history. London, Routledge, 2007. 188 p.

INGOLD, Tim. The eye of the storm: visual perception and the weather. Visual Studies, 20 (2). oct. London, Routledge, 2005. p. 97-104.

INGOLD, Tim. The perception of the environment: Essays on livelihood, dwelling and skill. London, Routledge, 2000. 
JACKS, Nilda. Repensando os estudos de recepção: dois mapas para orientar o debate. (Sessão Temática Antropologia e Comunicação). Ilha Revista de Antropologia, 10(2), ago-dez. 2008. Florianópolis, PPGAS/UFSC, 2010. p. 1736.

JORDAN, Pierre. Primeiros contatos, primeiros olhares. Cadernos de Antropologia e Imagem, 1. Rio de Janeiro, UERJ, 1995.

LARKIN, Brian. "The materiality of cinema theaters in Northern Nigeria". In: GINSBURG, F.; ABU-LUGHOD, L.; LARKIN, B. (eds.). Media Worlds: Anthropology on New Terrain. Berkeley, University of California Press, 2002.

LOIST, Skadi. "The Queer Film Festival Phenomenon in a Global Historical Perspective (the 1970s-2000s)”. In: FLECHET, Anaïs; GOETSCHEL, Pascale; HIDIROGLOU, Patricia; JACOTOT, Sophie; MOINE, Caroline; YERLAINE, Julie (orgs.). Une histoire des festivals: $\mathrm{XX}^{\mathrm{e}}-\mathrm{XXI}^{\mathrm{e}}$ siècle. Paris, Publications de la Sorbonne, 2013. p. 109-121.

LUTKEHAUS, Nancy; COOL, Jenny. "Paradigms Lost and Found: The 'Crisis of Representation' and Visual Anthropology". In: GAINES, Jane M. and RENOV, Michael (eds.). Collecting Visible Evidence. Minneapolis, University of Minnesota Press, 1999. p. 434-454.

MALUF, S.; MAGALHÃES, N.; CAGGIANO, S. Introdução: As mídias em múltiplas perspectivas. (Sessão Temática Antropologia e Comunicação.) Ilha Revista de Antropo-logia, 10(2), (ago-dez. 2008). Florianópolis, PPGAS/UFSC, 2010.

MARCUS, G.; FISCHER, M. Anthropology as a Cultural Critique. Chicago, The University of Chicago Press, 1986.

MOORE, Henrietta L. "Anthropological Theory at the Turn of the Century". In: MOORE, H. L. (ed.). Anthropological Theory Today. Cambridge, Polity, 1999.

MORENO, Antônio. A Personagem Homossexual no Cinema Brasileiro. $2^{\mathrm{a}}$ edição. Niterói: EdUFF/Funarte, 2002.

PIAULT, Marc-Henri. "Antropologia e Cinema”. In: Catálogo da Mostra Internacional do Filme Etnográfico, Rio de Janeiro, 1995.

PIAULT, Marc-Henri. "Real e Ficção: onde está o problema?” In: KOURY, Mauro Guilherme Pinheiro (Org). Imagem e Memória: Estudos em Antropologia Visual. Rio de Janeiro, Garamond, 2001.

RASTEGAR, Roya. The de-Fusion of good intentions. Outfest's Fusion Film Festival. GLQ: a Journal of Lesbian and Gay Studies, 15(3). Durham, Duke Un. Press, 2009. p. 481-497.

RUSSO, Vito. The Celluloid Closet. New York, Quality Paperback Book Club, 1987.

SHOHAT, Ella; STAM, Robert. Crítica da Imagem Eurocêntrica. São Paulo, Cosac-Naify, 2006. 
SILVA, Marcos Aurélio. Eduardo Coutinho e o cinema etnográfico para além da Antropologia. Cambiassú, 7. São Luís, UFMA, 2010. p. 161-174.

SILVA, Marcos Aurélio. A cidade de São Paulo e os territórios do desejo: uma etnografia do Festival Mix Brasil de Cinema e Vídeo da Diversidade Sexual. Revista Eco-Pós, 16 (3). Rio de Janeiro, UFRJ, 2013. p. 19-43.

STEWART, Kathleen. On the Politics of Cultural Theory: A Case for "Contaminated" Cultural Critique. Social Research, 58 (2), 1991. p. 395-412.

STOELTJE, Beverly J. "Festival". In: BAUMAN, Richard (org.). Folklore, Cultural Performances, and Popular Entertainments. New York/Oxford, Oxford University Press, 1992.

STRATHERN, Marilyn. Fora de Contexto. São Paulo, Terceiro Nome, [1987] 2013 .

STRATHERN, Marilyn. Partial Conections. Oxford, Altamira Press, 2004.

TURNER, Victor. "Liminal to Liminoid in play, flow, and ritual". In: From Ritual to Theatre: the human seriousness of play. New York, PAJ, 1982. p. 2060 .

TYLER, Stephen. "Post-Modern Ethnography: from Document of the Occult to Occult Document.” In: CLIFFORD, James; MARCUS, George E. (eds.). Writing Culture: the Poetics and Politics of Ethnography. Berkeley, Univ. of California, 1986. p. 122-140.

VEIGA, Roberta. O cinema como forma de comunicação. Geraes - Revista de Comunicação Social, 49. Belo Horizonte, FAFICH/UFMG, 1998. p. 31-37.

WAGNER, Roy. A Invenção da Cultura. Rio de Janeiro, CosacNaify, [1981] 2012.

XAVIER, Ismail (org.). A experiência do cinema. Rio de Janeiro, Graal, 1983.

XAVIER, Ismail. O olhar e a cena. São Paulo, CosacNaify, 2003.

ZIELINSKI, Gerald. Exhibition \& Community around the Queer Film Festival. (Paper). Conferência Seeking Queer Alliances: Resisting Dominant Discourses and Institu-tions. Varsóvia, Gender Studies Center \& American Studies Center/Warsaw University, 2006. 